\title{
A SYNCHRONOUS PRIMARY-SIDE DIMMING CONTROLLER FOR COLD- CATHODE FLUORESCENT LAMP BALLAST
}

Jenn-Jong Shieh

Department of Electrical Engineering, Ta Hwa Institute of Technology, Chunglin, Hsinchu, Taiwan 30743, R.O.C, eesjj@et4.thit.edu.tw

Follow this and additional works at: https://jmstt.ntou.edu.tw/journal

Part of the Electrical and Computer Engineering Commons

\section{Recommended Citation}

Shieh, Jenn-Jong (2005) "A SYNCHRONOUS PRIMARY-SIDE DIMMING CONTROLLER FOR COLD-CATHODE FLUORESCENT LAMP BALLAST," Journal of Marine Science and Technology: Vol. 13: Iss. 2, Article 5.

DOI: $10.51400 / 2709-6998.2110$

Available at: https://jmstt.ntou.edu.tw/journal/vol13/iss2/5

This Research Article is brought to you for free and open access by Journal of Marine Science and Technology. It has been accepted for inclusion in Journal of Marine Science and Technology by an authorized editor of Journal of Marine Science and Technology. 


\section{A SYNCHRONOUS PRIMARY-SIDE DIMMING CONTROLLER FOR COLD-CATHODE}

FLUORESCENT LAMP BALLAST

\section{Acknowledgements}

The work was supported in part under the financial support of the National Science Council, Republic of China, through its grant NSC 92-2213-E-233-009. Besides, the author gratefully thanks the professor C. T.

Pan of the National Tsing Hua University in Taiwan, for his valuable suggestions. 


\title{
A SYNCHRONOUS PRIMARY-SIDE DIMMING CONTROLLER FOR COLD-CATHODE FLUORESCENT LAMP BALLAST
}

\author{
Jenn-Jong Shieh
}

Key words: modeling, cold-cathode fluorescent lamp, dimming control.

\section{ABSTRACT}

In this paper, a rectified quasi-sinusoidal pulse width modulation (RQSPWM) controller is first proposed for the cold-cathode fluorescent lamp (CCFL) ballast to achieve a synchronous primary-side dimming control. It is seen that, with the novel controller, not only the lamp flickering problem and the thermometer effect can be eliminated but also the useful photo-coupler in secondary side can be avoided to reduce cost. Then, small signal models of the CCFL ballast and the proposed RQSPWM dimming controller are derived to analyze the performance of the ballast system and help corroborate hardware loop measurements. Finally, a prototype is constructed for verifying the effectiveness of the proposed closed-loop dimming control strategy.

\section{INTRODUCTION}

The proliferation of portable devices, such as laptops, notebook computers and personal digital assistants (PDA) are developed fast recently, which places an even increasing demand on display technology [218]. The liquid crystal display (LCD) with cold-cathode fluorescent lamp (CCFL) back lighting satisfies the requirements on display performance, size and efficiency best. However, the CCFL is inherently a complex transducer and its characteristic is seriously dependent on gas elements, temperature, lamp size, driving waveform, lamp current and its neighboring components [7]. Generally, the current source push-pull topology with the Royer inverter can be realized as the driver of CCFL [2, 12]. When dimming capability, normally a very desirable feature for variable applications, is required, a current-fed buck-derived prestage converter can be adopted directly [5]. Unfortunately, a lot of problems such as instability in control, luminance loss, flickering and severe electromagnetic interference

Paper Submitted 02/06/04, Accepted 02/24/05. Author for Correspondence: Jenn-Jong Shieh.E-mail: eesjj@et4.thit.edu.tw.

*Department of Electrical Engineering, Ta Hwa Institute of Technology, Chunglin, Hsinchu, Taiwan 30743, R.O.C.
(EMI) could be caused. Lin et al. proposed a direct closed-loop dimming control with the Royer circuit to avoid the flickering phenomenon and suppress the EMI [10]. Since the feedback loop without an extra desired compensator, some disadvantages, e.g., limited bandwidth, high maximum overshoot which could hurt the CCFL, and narrow dimming control range for environmental backlight regulation that could lead to instability control, exist in this ballast. Although the asymmetrical pulse width modulation with series resonant inverter can provide a wider dimming control and easier in designing the filter for EMI by the duty ratio control [13], however, these merits are obtained at the expense of an increased complexity in design and analysis. A closed-loop feedback charge-pump controller with the Royer inverter with a view to achieve wide-range control was also presented by Hsieh et al. [6]. Nevertheless, derivation of the corresponding mathematical model of the ballast and the related subjects in synchronous processes of PWM controller and the integration of these into the ballast are not covered.

In this paper, a rather simple closed-loop-based synchronous primary-side dimming controller for the CCFL ballast is proposed to overcome the above-mentioned problems. Contents of the following sections are outlined as follows. The description of the operation principle of the proposed ballast will be given in Section 2. In Section 3, the modeling for the proposed rectified quasi-sinusoidal pulse width modulation (RQSPWM) CCFL ballast is made. A prototype hardware circuit is constructed and experimental results are presented for illustration in Section 4. Some conclusions are offered in Section 5 and guidelines for selecting the LC parameters are provided in the Appendix.

\section{CIRCUIT DESCRIPTION AND OPERATION}

Figure 1 shows the proposed closed-loop compensator-based synchronous primary-side dimming controller for the CCFL ballast. To protect circuit components, particularly $S_{1}$ and $S_{2}$, from turn-on and 
turn-off transients, Zener diodes $Z_{1}$ and $Z_{2}$ are adopted. The bias current driving $S_{1}$ and $S_{2}$ in conjunction with inductor $L$ allows current to flow through the primary winding. Because of using resistor $R_{1}$ coupled to connect with transistor $S_{1}$, as a result, switch $S_{1}$ will be turned on before transistor $S_{2}$ at the starting. As current begins flowing through transistor $S_{1}$, most of the current in inductor $L$ flows in primary winding $N_{1 a}$. The current in winding $N_{1 a}$ causes the flux density within the core of transformer to increase so a voltage will be induced in bias-winding $N_{3}$ and $S_{1}$ transistor will be kept saturated. As the flux gets saturated, the induced voltage on biaswinding $N_{3}$ will be reversed which in turns drives transistor $S_{2}$ into saturation and allows current to flow through the collector of transistor $S_{2}$ and primary winding $N_{1 b}$. Thus, the Royer inverter circuit will continue the self excitation in this way. Typical waveforms in this circuit are shown in Figure 2 for reference.

Assume that the parasitic losses are neglected, and then the input power will be equal to the lamp power. i.e.

$$
v_{G(a v g)} i_{L(a v g)}=v_{l a m p(r m s)} i_{l a m p(r m s)}
$$

Since the voltage of the secondary winding is a quasi-sinusoidal waveform, the average input average voltage $v_{G(\text { avg })}$ can be derived [1] as

$$
v_{G(a v g)}=\frac{N_{1}}{N_{2}} \frac{\sqrt{2}}{\pi} v_{\text {out }(\mathrm{rms})}, N_{1}=N_{1 a}=N_{1 b}
$$

Since the dynamic impedance of CCFL is negative after firing, a ballast capacitor $C_{B}$ must be added to stabilize the lamp current. Additionally, the reactance of $C_{B}$ must be designed to be greater than twice the CCFL resistance in practical application [7]. However, the larger the $C_{B}$ is, the larger size of the ballast is.

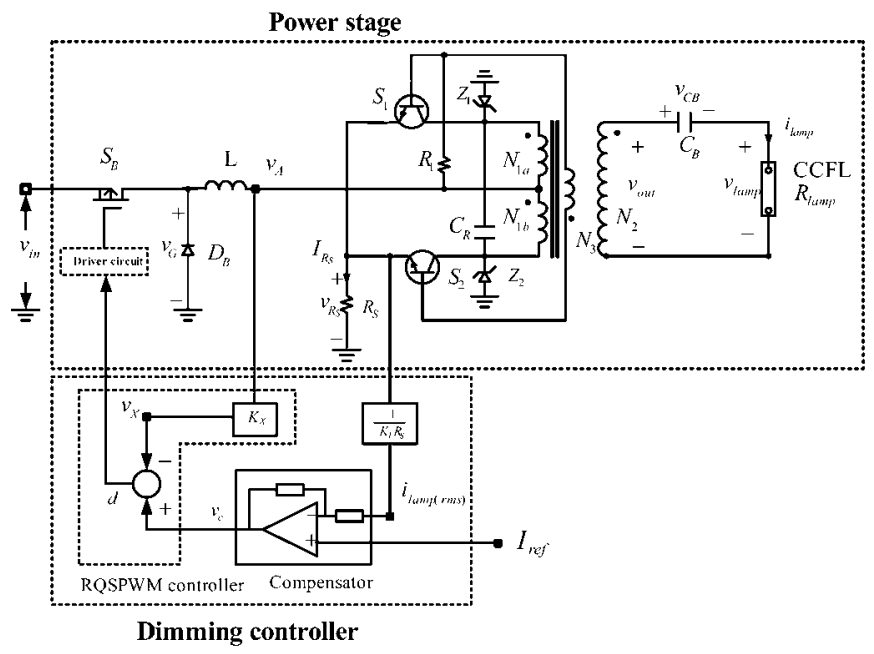

Fig. 1. The proposed CCFL ballast.
Trade-off the above conditions together with an extra $25 \%$ margin, one can choose

$$
v_{C B(r m s)}=2.5 v_{l a m p(r m s)}
$$

On the other hand, from Fig. 1 one can see that $i_{L(a v g)}=I_{R_{S}}$ and $v_{\text {out }(r m s)}=\sqrt{v_{C B(r m s)}^{2}+v_{\text {lamp }(r m s)}^{2}}$. Based on these results and substituting (2) and (3) into (1), one can obtain

$$
I_{R_{S}}=K_{I} i_{\text {lamp }(r m s)}, K_{I}=\frac{N_{2}}{N_{1}} \pi \sqrt{\frac{2}{29}}
$$

It is obvious that, from (4), $i_{\text {lamp (rms) }}$ is proportional to $I_{R_{S}}$. Hence, the dimming control can be accomplished by sensing the current flowing through the sensing resistor, $R_{s}$, on the primary side and a compensator together with a repetitive waveform $v_{X}$, which is proportional to $v_{A}$, can be adopted to achieve $i_{l a m p(r m s)}=I_{r e f}$ by controlling the duty cycle of Buck switch $S_{B}$. Notice that not only the waveform of $v_{A}$ is with double resonant frequency of the Royer inverter $\omega_{s}$ but also approximately resembles a rectified quasi-sinusoidal waveform. In addition, the resulting RQSPWM switching frequency of $S_{B}$ is synchronous to $\omega_{s}$ that will effectively eliminate the lamp flickering problem encountered in the conven-

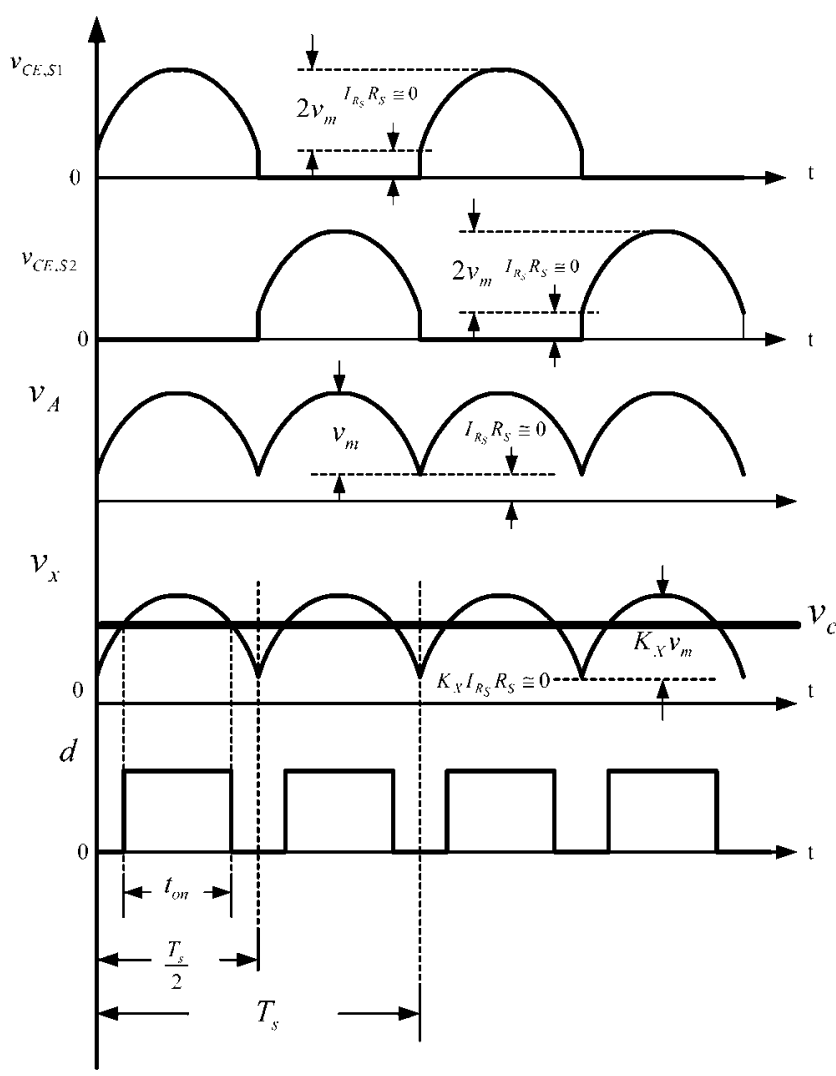

Fig. 2. Typical waveforms in this circuit. 
tional one. Furthermore, since $S_{B}$ is controlled by directly feeding back the voltage across $R_{s}$, the proposed controller without using any photocoupler, rectifiers and/or filters, and what is more, the feedback loop is not only more stable than the conventional ballast but also with less cost.

\section{MODELING AND CONTROL OF THE PROPOSED CCFL BALLAST}

The small-signal model of a system is a rather useful model to analyze the performance of dynamic behavior before their controller is implemented. The power stage of the CCFL ballast and the proposed RQSPWM controller in Figure 1 are linearized and perturbed to achieve their small signal models. Based on the models, the compensator in feedback loops can be properly designed or adjusted to achieve the desired steady-state and transient specifications.

\section{Power stage}

As an illustration, Figure 3 shows the simplified parallel equivalent circuit of the power stage of Figure 1 viewed from the secondary side. For reference, the relationships among $v_{X}, d, v_{G}$ and $v_{G}^{\prime}$ are shown in Figure 4. From Figure 3, one can obtain the corresponding state equations as follows.

$$
\frac{d}{d t}\left[\begin{array}{c}
i_{L}^{\prime} \\
v_{p} \\
i_{p}
\end{array}\right]=\left[\begin{array}{ccc}
-\frac{R_{s}^{\prime}}{L^{\prime}} & -\frac{1}{L^{\prime}} & 0 \\
\frac{1}{C_{p}} & \frac{-1}{R_{p}} & 1 \\
0 & \frac{1}{L_{p}} & 0
\end{array}\right]\left[\begin{array}{c}
i_{L}^{\prime} \\
v_{p} \\
i_{p}
\end{array}\right]+\left[\begin{array}{c}
\frac{v_{G}^{\prime}}{L^{\prime}} \\
0 \\
0
\end{array}\right]
$$

where

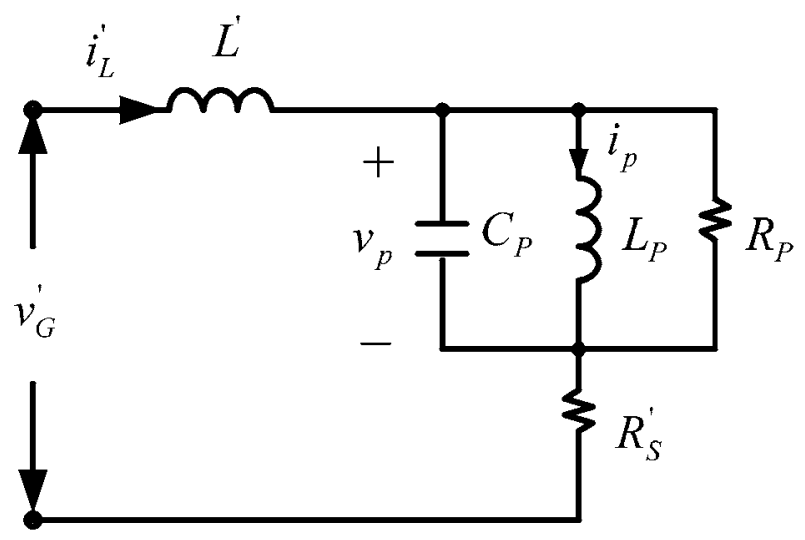

Fig. 3. Simplified equivalent circuit of the power stage with parameters referring to the load side.

$$
\begin{aligned}
& L_{p}=N^{2} L_{m} \\
& C_{p}=\frac{4 C_{R}}{N^{2}}+\frac{C_{B}}{1-\omega_{s}^{2} C_{B}^{2} R_{\text {lamp }}^{2}} \\
& R_{p}=\frac{1}{1-\omega_{s}^{2} C_{B}^{2} R_{\text {lamp }}}-R_{\text {lamp }} \\
& L^{\prime}=N^{2} L \\
& R_{s}^{\prime}=N^{2} R_{s}
\end{aligned}
$$

in which $R_{\text {lamp }}$ represents the steady-state lamp resistance, $N \equiv \frac{N_{2}}{N_{1}}$ and $\omega_{s}=\frac{2 \pi}{T_{s}}$.

The input voltage $v_{G}^{\prime}$ can be represented by Fourier series with the fundamental frequency of $\omega_{s}$. Since all the harmonics above the fundamental component will be effectively attenuated, hence only the fundamental component needs to be considered. The fundamental sinusoidal component is given as follows.

$$
v_{s}=\frac{4}{\pi}\left(N v_{i n}\right) \sin \left(\frac{\pi}{2} d\right) \sin \omega_{s} t
$$

To obtain the corresponding small-signal model,

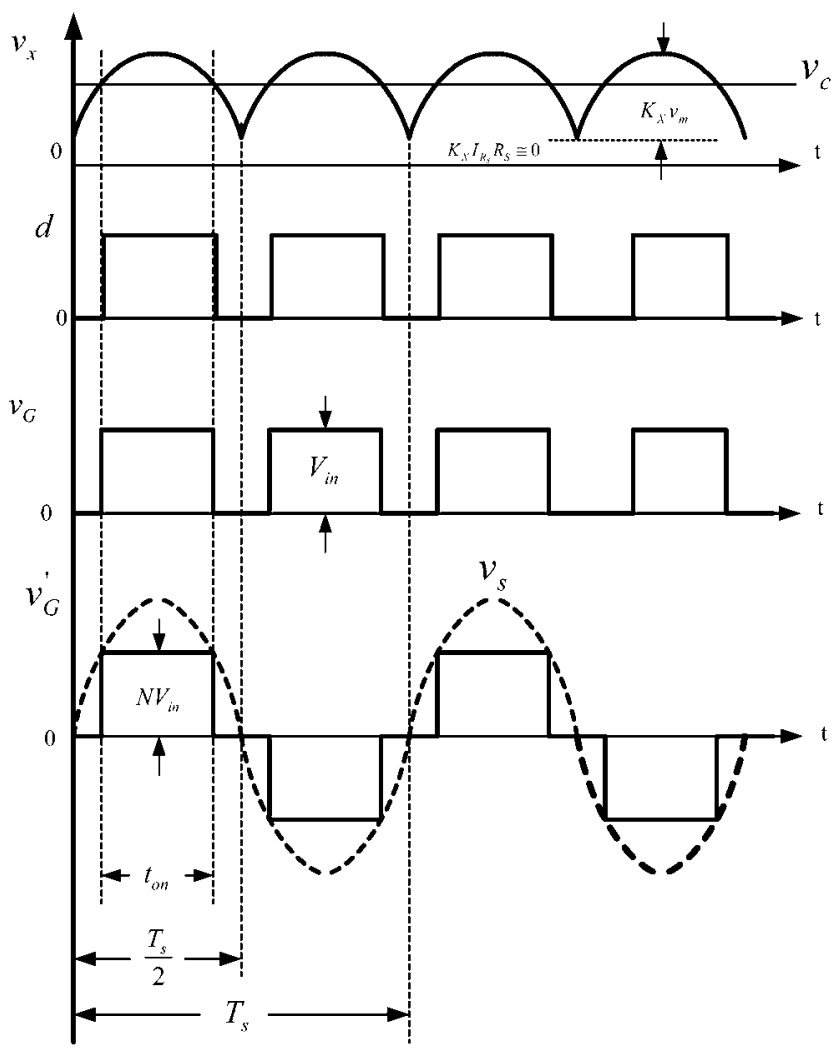

Fig. 4. Relationships among $v_{X}, d, v_{G}$ and $v_{G}^{\prime}$. 
one can adopt the "extended describing function technique" [19] approach, namely let

$$
f=f_{d} \cos \omega_{s} t+f_{q} \sin \omega_{s} t
$$

where

$$
\begin{aligned}
& f \in\left\{\begin{array}{lll}
i_{L}^{\prime} & v_{p} & i_{p}
\end{array}\right\} \\
& f_{d} \in\left\{\begin{array}{lll}
i_{L d}^{\prime} & v_{p d} & i_{p d}
\end{array}\right\} \\
& f_{q} \in\left\{\begin{array}{lll}
i_{L q}^{\prime} & v_{p q} & i_{p q}
\end{array}\right\}
\end{aligned}
$$

From (12) if one decomposes $f$ into sine and cosine components, $f_{d}$ and $f_{q}$ amplitudes can be assumed to consist of a steady-state component together with small variations. Hence, one can define the following perturbation equations:

$$
\begin{aligned}
& f_{d}=F_{d}+\hat{f}_{d} \\
& f_{q}=F_{q}+\hat{f}_{q} \\
& v_{G}^{\prime}=V_{G}^{\prime}+\hat{v}_{G}^{\prime}=N V_{i n}+N \hat{v}_{i n} \\
& d=D+\hat{d}
\end{aligned}
$$

By substituting (11) and (16)-(19) into (5) and using the harmonic balance procedure and linearizing these equations [19], one can obtain the following DC model and small-signal model.

\section{DC model:}

$$
0=A_{0} X_{0}+B_{0} U_{0}, V_{R_{1}}=C_{0} X_{0}
$$

where

$$
A_{0}=\left[\begin{array}{cccccc}
\frac{-R_{s}^{\prime}}{L^{\prime}} & -\omega_{s} & \frac{-1}{L^{\prime}} & 0 & 0 & 0 \\
\omega_{s} & \frac{-R_{s}^{\prime}}{L^{\prime}} & 0 & \frac{-1}{L^{\prime}} & 0 & 0 \\
\frac{1}{C_{p}} & 0 & \frac{-1}{C_{p} R_{p}} & -\omega_{s} & \frac{-1}{C_{p}} & 0 \\
0 & \frac{1}{C_{p}} & \omega_{s} & \frac{-1}{C_{p} R_{p}} & 0 & \frac{-1}{C_{p}} \\
0 & 0 & \frac{-1}{L_{p}} & 0 & 0 & -\omega_{s} \\
0 & 0 & 0 & \frac{-1}{L_{p}} & \omega_{s} & 0
\end{array}\right]
$$

$$
\begin{aligned}
X_{0} & =\left[\begin{array}{llllll}
I_{L d}^{\prime} & I_{L q}^{\prime} & V_{p d} & V_{p q} & I_{p d} & I_{p q}
\end{array}\right]^{T} \\
B_{0} & =\left[\begin{array}{llllll}
0 & 1 & 0 & 0 & 0 & 0
\end{array}\right]^{T} \\
U_{0} & =\frac{4}{\pi} N V_{i n} \sin \left(\frac{\pi}{2} D\right) \\
C_{0} & =R_{s}\left[\begin{array}{llllll}
1 & 1 & 0 & 0 & 0 & 0
\end{array}\right]^{T}
\end{aligned}
$$

\section{Small signal model:}

$$
\dot{x}=A x+B \hat{v}_{i n}+E \hat{d}+F \hat{\omega}_{s}, v_{R_{S}}=C x
$$

where

$$
\begin{aligned}
& \dot{x}=\left[\begin{array}{llllll}
\hat{i}_{L d}^{\prime} & \hat{i}_{L q}^{\prime} & \hat{v}_{p d} & \hat{v}_{p q} & \hat{i}_{p d} & \hat{i}_{p q}
\end{array}\right]^{T} \\
& A=A_{0} \\
& B=\sin \left(\frac{\pi}{2} D\right) B_{0} \\
& C=C_{0} \\
& E=\frac{4}{\pi} N V_{i n} \cos \left(\frac{\pi}{2} D\right)\left[\begin{array}{llllll}
0 & 1 & 0 & 0 & 0 & 0
\end{array}\right]^{T} \\
& F=\left[\begin{array}{llllll}
-I_{L q}^{\prime} & I_{L d}^{\prime} & -V_{p q} & V_{p d} & -I_{p q} & I_{p d}
\end{array}\right]^{T}
\end{aligned}
$$

Taking the Laplace transformation of (26) one can obtain the signal $v_{R_{S}}(s)$ (which denotes the equivalent lamp RMS current) as follows.

$$
\begin{aligned}
v_{R_{S}}(s) & =R_{s} \hat{i}_{L d}^{\prime}(s)+R_{s} \hat{i}_{L q}^{\prime}(s) \\
& =R_{s} \frac{\hat{i}_{L d}^{\prime}(s)}{\hat{d}(s)} \hat{d}(s)+R_{s} \frac{\hat{i}_{L d}^{\prime}(s)}{\hat{d}(s)} \hat{d}(s) \\
& \equiv R_{s} F_{L d}(s) \hat{d}(s)+R_{s} F_{L q}(s) \hat{d}(s)
\end{aligned}
$$

\section{The RQSPWM controller}

In the proposed RQSPWM controller, the control voltage $v_{c}$, which is the output of the error amplifier, is compared with a rectified quasi-sinusoidal waveform as shown in Figure 2, to achieve the following duty ratio.

$$
d \equiv \frac{t_{o n}}{\frac{T_{s}}{2}}=1-\frac{\sin ^{-1} \frac{v_{c}}{K_{X} v_{m}}}{\pi}, \frac{v_{c}}{K_{X} v_{m}}<1
$$

To obtain the theoretical transfer function of the RQPPWM controller, one can take the differential of (34) as follows:

$$
\hat{d}=\frac{\partial d}{\partial v_{m}} \hat{v}_{m}+\frac{\partial d}{\partial v_{r}} \hat{v}_{c}
$$




$$
=\frac{V_{c}}{\pi V_{m}^{2} \sqrt{1-\left(\frac{V_{c}}{K_{X} v_{m}}\right)^{2}}} \hat{v}_{m}-\frac{1}{\pi V_{m} \sqrt{1-\left(\frac{V_{c}}{K_{X} v_{m}}\right)^{2}}} \hat{v}_{c}
$$$$
\equiv K_{m d} \hat{v}_{m}-K_{c d} \hat{v}_{c}
$$

Since $\hat{v}_{m}$ is proportional to $\hat{i}_{\text {lamp }}$, (35) implies small variations of lamp current $\hat{i}_{\text {lamp }}$ can be automatically compensated by the proposed dimming control. Certainly, a wide dimming range can be easily provided for environmental backlight regulation.

In summary, from the above procedure, one can obtain the corresponding block diagram as shown in Figure 5. Based on Figure 5, one can check the stability of the closed loop system and simulate and analyze the transient behavior of the ballast system.

\section{SOME EXPERIMENTAL RESULTS}

To illustrate the significance and facilitate the understanding of the theoretical described in previous sections, a prototype with the following parameters is constructed.

$v_{\text {in }}: 10 \sim 14.4$ (typical vaule) $\sim 22 \mathrm{~V}$,

$S_{B}$ : RFP15P50(15 A, $\left.50 \mathrm{~V}, 0.15 \Omega\right), S_{1}$ and $S_{2}$ : HA3669A $\left(h_{F E, \text { min }}=240, V_{B E, \text { cut }- \text { in }}=0.55 \mathrm{~V}, V_{B E, \text { sat }}=\right.$ $0.9 \mathrm{~V})$,

Transformer (Ferrite core, $N_{1}: N_{2}: N_{3}=12: 1800$ : $3, L_{m}=20 \mu \mathrm{H}$ ), $R_{1}=5.1 \mathrm{~K} \Omega, \mathrm{L}=150 \mu \mathrm{H}$ (MPPcore), $C_{B}$ $=22 \mathrm{pF}, C_{R}=150 \mathrm{nF}, R_{S}=0.5 \Omega$.

\section{CCFL:}

Size: $18 \mathrm{~mm} \phi \times 292 \mathrm{~mm}$,
Maximum dissipation power $P_{C C F L \text {, max }}: 5 \mathrm{~W}$, Maximum open output voltage $v_{\text {out }(r m s, \max )}: 1,800 \mathrm{~V}$, Starting voltage $v_{\text {start }(r m s)}: 1,400 \mathrm{~V}$, Operating frequency: $f_{s}=45 \mathrm{KHz}$.

For reference, critical values of $L, C_{B}$ and $C_{R}$ of (A1), (A2) and (A3) and $L_{m}$ (A4), namely $112.3 \mu \mathrm{H}$, $14.7 \mathrm{pF}, 116 \mathrm{nF}$ and $20.2 \mu \mathrm{H}$, respectively are also calculated. It is seen that the chosen values indeed satisfy the above bounds. It is also important to note that the larger the $C_{R}$ is, the more sinusoidal the waveforms are and the better the lamp life cycle is, but the copper losses of the primary windings of the transformer and the size of the ballast are larger. Hence, the trade-off between (A3) and (A4) is a prerequisite for practical applications. To explore the characteristics of the proposed ballast, the waveforms of $v_{A}, v_{C E 1}, v_{\text {out }}$ and $i_{\text {lamp }}$, are recorded separately. Figures 6 and 7 show the measured results with two different $I_{\text {ref }}$ under the typical input voltage. From Figures 6 and 7, one can see that not only the output lamp voltage and lamp current waveforms are much closer to pure sinusoidal waveform, but also the shape, frequency and magnitude of waveforms $v_{A}, v_{C E 1}, v_{\text {out }}$ and $i_{\text {lamp }}$ are in good agreement with the expected results.

\section{CONCLUSION}

To achieve wide range dimming control, suppress the lamp flickering problem and thermometer effect and stabilize the dynamic feedback regulator for lamp luminance in uniform distribution, a new synchronous primary-side dimming controller for the CCFL electronic ballast is proposed. Not only the extended describing function technique is successfully used to simplify

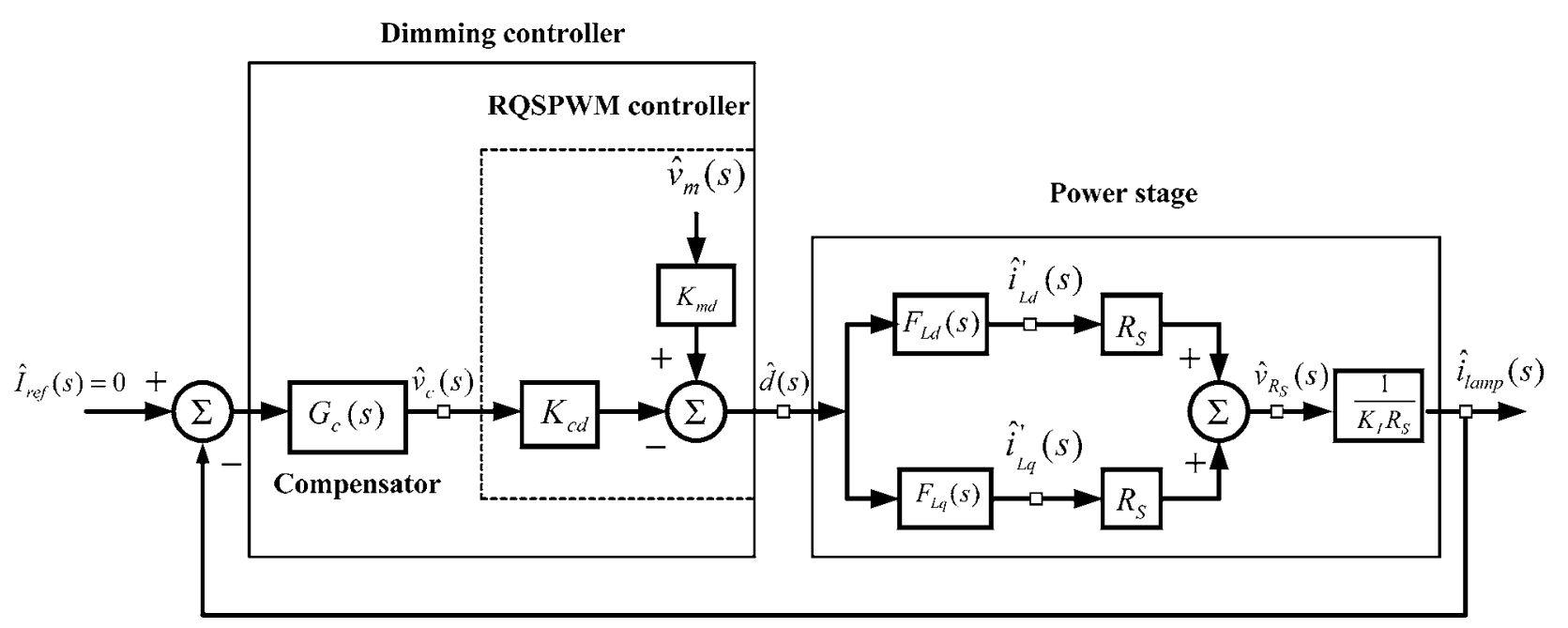

Fig. 5. The closed loop small-signal block diagram. 


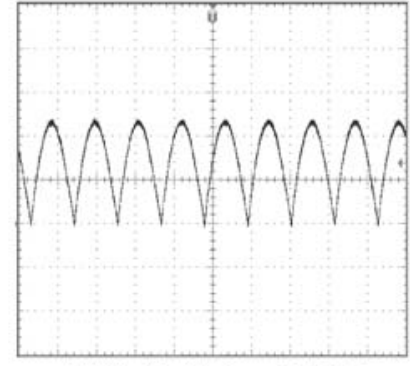

(5V/div, 10us/div, Freq. $=88.98 \mathrm{KHz})$

(a) $v_{4}$

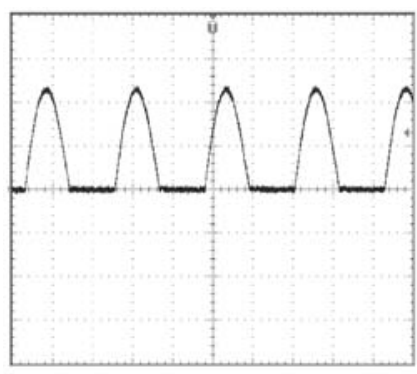

(10V/div, 10us/div, Freq. $=44.71 \mathrm{KHz})$

(b) $v_{c e, s 1}$

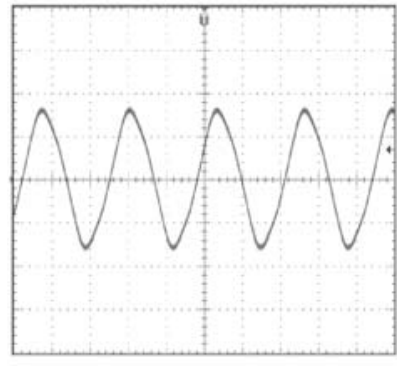

(1KV/div, 10us/div, Freq. $=43.73 \mathrm{KHz}$ )

(c) $v_{\text {ow }}$

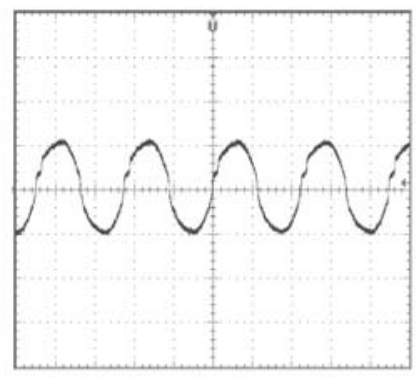

$(5 \mathrm{~mA} /$ div, $10 \mathrm{us} / \mathrm{div}$, Freq. $=44.54 \mathrm{KHz})$

(d) $i_{\operatorname{lam} p}$
Fig. 6. Measured key waveforms when $I_{r e f}$ is $2.4 \mathrm{~A}$.

greatly the modeling process without sacrificing the accuracy within the valid frequency range, but also the steady-state and small-signal analyses are derived. Some design guidelines for selecting the power parameters are also described briefly in Appendix. The validity of the proposed CCFL electronic ballast has been verified on an experimental prototype.

\section{ACKNOWLEDGEMENTS}

The work was supported in part under the financial support of the National Science Council, Republic of China, through its grant NSC 92-2213-E-233-009. Besides, the author gratefully thanks the professor C. T. Pan of the National Tsing Hua University in Taiwan, for his valuable suggestions.

\section{APPENDIXES}

Some guidelines for selecting the LC parameters are provided below.

\section{A.1 Storage inductor $L$}

To prevent the Buck converter from being oper-

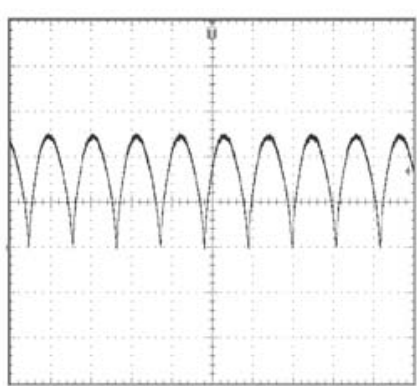

$(5 \mathrm{~V} / \mathrm{div}, 10 \mathrm{u} / \mathrm{sec}$, Freq. $=92.34 \mathrm{KHz})$

(a) $v_{1}$

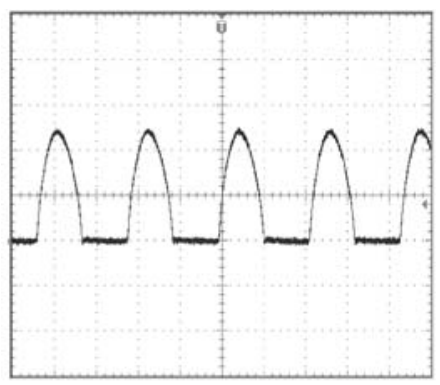

$(10 \mathrm{~V} / \mathrm{div}, 10 \mathrm{u} / \mathrm{sec}$, Freq. $=45.98 \mathrm{KHz})$

(b) $v_{\text {CF,S1 }}$
(1KV/div, 10us/div, Freq. $=45.26 \mathrm{KHz})$

(c) $v_{\text {our }}$

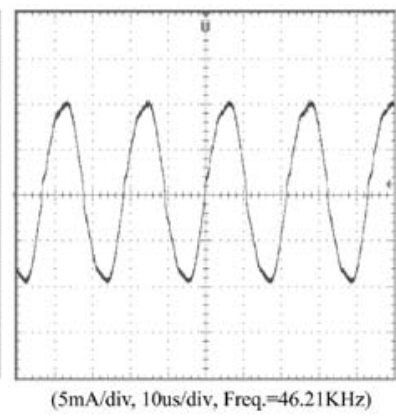

(d) $i_{\text {hesp }}$

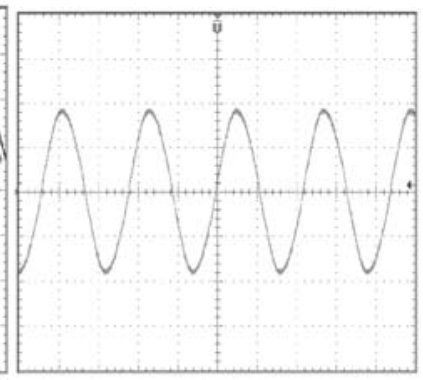

Fig. 7. Measured key waveforms when $I_{r e f}$ is $4.4 \mathrm{~A}$.

ated in discontinuous conduction mode (DCM), the ripple current of the current $i_{L}$ should be much less than the averaged dc current, say $15 \%$ of the maximum DC current here. Hence, the $L$ can then be estimated as follows.

$$
L \geq t_{\text {off }, \max } \frac{v_{G \text { (avg, max })}}{0.15 i_{L(\text { avg, } \max )}}, t_{\text {off, } \max }=\left(1-\frac{v_{G(\text { avg, } \max )}}{v_{\text {in, } \max }}\right) \frac{T_{s}}{2}
$$

where $t_{\text {off, max }}$ denotes the maximum off-time for the $S_{B}$.

\section{A.2 Ballast capacitance $C_{B}$}

Since $v_{C B(r m s)}=2.5 v_{l a m p(r m s)}$ is adopted here and the smaller the lamp currents is, the higher the $R_{\text {lamp }}$ is. Hence

$$
\begin{gathered}
C_{B}>\frac{1}{2.5 \omega_{s} R_{\text {lamp }, \min }} \\
=\frac{i_{\text {lamp }, \max }}{2.5 \omega_{s} R_{C C F L, \max }}
\end{gathered}
$$

where $P_{C C F L \text {, max }}$ denotes the maximum dissipation power of the CCFL. 


\section{A.3 Resonant capacitance $C_{R}$ and magnetizing induc- tance $L_{m}$}

To keep the life cycle of the CCFL and ensure that for entire dimming range the lamp current has a good performance, a sinusoidal voltage waveform will be provided. In other words, the characteristic roots of Fig. 3 should be properly designed to guarantee complex conjugate pairs. Thus,

$$
\begin{aligned}
& C_{R}>\frac{C_{B} N^{2}}{8} \frac{\left(2-\omega_{r} C_{B} R_{\text {lamp }}\right)}{\left(1-\omega_{r}^{2} C_{B}^{2} R_{\text {lamp }}^{2}\right)} \\
& K_{I}=\frac{N_{2}}{N_{1}} \pi \sqrt{\frac{2}{29}}
\end{aligned}
$$

where $\omega_{r}=\frac{1}{\sqrt{L_{p} C_{p}}}$.

\section{REFERENCES}

1. Bruning, G., "A Comparative Introduction of a New High Voltage Resonant Oscillator," Proceedings of the IEEE Applied Power Electronics Conference and Exposition, Orlando, FL, pp. 76-82 (1986).

2. Chen, W., "Series-Parallel Resonant Forward Inverter as a Cold Cathode Fluorescent Lamp (CCFL) Driver," Proceedings of the IEEE Applied Power Electronics Conference and Exposition, Dallas, TX, pp. 943-947 (2002).

3. Cummings, J. and Kates, B.K., "Voltage Regulator with Double Synchronous Bridge CCFL Inverter,' U.S. Patent No. 6108215 (2000).

4. George, C.H., "Dimmable Backlight System," U.S. Patent No. 6198234 B1 (2001).

5. Gulko, M. and Ben-Yaakov, S., "Current-sourcing Pushpull Parallel-resonance Inverter (CS-PPRI): Theory and Application as a Discharge Lamp Driver," IEEE T. Ind. Electron., Vol. 41, No. 3, pp. 285-291 (1994).

6. Hsieh, G.C., Lin, C.H., Lin, C.H., and Hsieh, H.I., "Primary-Side Charge-pump Dimming Controller for the Cold-cathode Fluorescent Lamp Ballast," Proceedings of the IEEE International Conference on Electrical and Electronic Technology, Singapore, pp. 717-723 (2001).

7. Jordan, M. and O'Connor, J.A., "Resonant Fluorescent Lamp Converter Provides Efficient and Compact Solution," Proceedings of the IEEE Applied Power Electronics Conference and Exposition, San Diego, CA, pp. 424-431 (1993).
8. Kazimierczuk, M.K., "Class D Voltage-Switching MOSFET Power Amplifier," IEE Proceedings: Electric Power Applications, Vol. 138, No. 6, pp. 285-296 (1991).

9. Kim, C.J., Ji, J.G., and Yoon, S.Y., "A Study on the Design and Performance of Electronic Ballast for CCFL Dimming Control with Frequency Modulation," Proceedings of the Sixth International Conference on Electrical Machines and Systems, Beijing, China, pp. 453456 (2003).

10. Lin, M.S., Ho, W.J., Shih, F.Y., Chen, D.Y., and Wu, Y.P., "A Cold-cathode Fluorescent Lamp Driver Circuit with Synchronous Primary-Side Dimming Control," IEEE T. Ind. Electron., Vol. 45, No. 2, pp. 249255 (1998).

11. Lin, Y.L., "High-efficiency Adaptive DC/AC Converter," U.S. Patent No. 6108215 (2000).

12. Lin, Y.L. and Witulski, A.F., "Analysis and Design of Current-fed Push-pull Resonant Inverters-cold Cathode Fluorescent Lamp Drivers," IEEE Industry Applications Conference Record, San Diego, CA, pp.2149-2152 (1996).

13. Moo, C.S., Cheng, H.L., and Chang, Y.N., "A Singlestage High-power Factor Dimmable Electronic Ballast with Asymmetrical Pulse-Width-Modulation for Fluorescent Lamps," Proceedings of the IEEE Industrial Electronics Society Annual Conference, Chicago, IL, pp. 2273-2278 (2000).

14. Nalbant, M.K., "A new CCFL Inverter Circuit for AMLCD Panels Results in Significantly Higher Efficiency and Brightness," Second International Workshop on Active Matrix Liquid Crystal Displays, Bethlehem, PA, pp. 133-136 (1995).

15. Rolston, W., "Circuit for Obtaining a Wide Dimming Ratio from a Royer Inverter," U.S. Patent No. 6215680B1 (2001).

16. Seidel, A.R., Bisogno, F.E., Pinheiro, H., and Do Prado, R.N., "Self-oscillating Dimmable Electronic Ballast," IEEE T. Ind. Electron., Vol. 50 , No. 6 , pp. 1267-1274 (2003).

17. Tsai, Y.H., "Multiple CCFL Current Balancing Scheme for Single Controller Topologies," U.S. Patent No. 6459216 (2002).

18. Wey, C.D., Jong, T.L., and Pan, C.T., "Design and Analysis of an SLPT-Based CCFL Driver," IEEE T. Ind. Electron., Vol. 50, No. 1, pp. 208-217 (2003).

19. Yang, E., Lee, F.C., and Jovanovic, M.M., "Extended Describing Function Technique Applied to the Modeling of Resonant Converters," Proceedings of the Virginia Power Electronics Center Seminar, Blacksburg, VA, pp. 179-191 (1991). 